\title{
Experimental Investigation of Performance of Diesel Engine Working On Diesel and Neem Oil Blends
}

\author{
Lovekush Prasad $^{1}$, Dr. Alka Agrawal ${ }^{2}$ \\ ${ }^{1,2}$ Department of mechanical engineering, University institute of Technology, RGPV Bhopal, Madhya Pradesh, \\ India
}

\begin{abstract}
The depletion of oil resources as well as the environmental regulation has led to the development of alternate energy sources. In this present work the performance characteristics of a single cylinder diesel engine when fulled with blends of neem oil and diesel are evaluated. Experiments were conducted with different blends $(B 10 \& B 20)$ of neem oil and diesel as various loads. The results show that the brake thermal efficiency of diesel is slightly higher at all loads followed by blends of neem oil and diesel, it has been established that $20 \%$ of neem oil biodiesel can be use as a substitute for diesel without any engine modification thus neem oil as non-edible oil can be a good renewable raw material for biodiesel production.
\end{abstract}

Keywords- alternate fuels, blends, neem oil, performance, transesterification.

\section{Introduction}

Conventional energy sources such as oil, coal and natural gas have limited reserves that are expected not to lost for an extended period. World primary demand is projected to increase by $1.5 \%$ per year between 2007 to 2030, from just over 12,000 million tonnes of oil equivalent to16800 million tones-as overall increase of $40 \%$. As world reserves of fossil fuels and raw material are limited, it has stimulated active research interest in non petroleum and non polluting fuels. Diesel engines are the major source of power generation and transportation hence diesel is being used extensively, but due to the gradual impact of environmental pollution there is an urgent need for suitable alternate fuels for use in diesel engine without any modification.

There are different kinds of vegetable oils and biodiesel have been tested in diesel engines its reducing characteristic for green house gas emissions. Its help on reducing a country's reliance on crude oil imports its supportive characteristic on agriculture by providing a new market for domestic crops, its effective lubricating property that eliminates the need of any lubricate additive and its wide acceptance by vehicle manufacturers can be listed as the most important advantages of biodiesel fuel. There are more than 350 oil bearing crops identified, among which only Jatropha, ongamia, sunflower, Soyabean, cottonseed, rapeseed, palm oil and peanut oil are considered as potential alternative fuels for diesel engines. The present study aims to investigate the use of neem oil blend with diesel as an alternate fuel for compression ignition engine.

\section{Materials And Methods}

Biodiesel is the ester of vegetable oils produced through a process called transesterification. Transesterification is a chemical reaction which occurs between triglyceride and methyl alcohol in the presence of potassium hydroxide $(\mathrm{KOH})$. It consists of a sequence of three consecutive reactions where triglycerides are converted to diglycerides; diglycerides are converted to monoglycerides followed by the conversion of monoglycerides to glycerol. In each step an ester is produced and thus three ester molecules are produced from one molecule of triglyceride.

Neem oil used in the present investigation was taken from the local market of Bhopal, Madhya Pradesh, India and filtered by cheesecloth to remove solid particles. The moisture content was removed by heating the oil in an oven up to $110^{\circ} \mathrm{C}$ for one hour now the oil is taken in a round bottom flask and heated around $50-60^{\circ} \mathrm{C}$ on a hot plate having magnetic stirrer arrangement, then methanol and potassium hydroxide are added to the oil. The mixture was stirred continuously. Alcohol to vegetable oil molar ratio is one of the important factors that affect the conversion efficiency of the process for the transesterification process 3 mol of alcohol are required for each mole of the oil. However, in practice the molar ratio should be higher than this theoretical ratio in order to drive the reaction towards early completion.

After the completion of reaction, the products are allowed to separate into two layers, the lower layer contains glycerol and the top layer contains ester which is separated and purified using water. Water is sprayed over the ester and stirred gently and allowed to settle in the separating funnel, the lower layer is discarded and upper layer (purified biodiesel) is separated.

Biodiesel (methyl esters of neem oil) have several outstanding advantages among other new-renewable and clean engine fuel alternatives. The properties of diesel and biodiesel (neem oil methyl ester) used in present investigation were compared with diesel fuel in Table.1 
Experimental Investigation Of Performance Of Diesel Engine Working On Diesel And Neem Oil

Table.1 Properties of diesel and biodiesel

\begin{tabular}{|l|l|l|}
\hline Properties & Diesel & $\begin{array}{l}\text { Biodiesel(Neem oil methyl } \\
\text { ester) }\end{array}$ \\
\hline Specific gravity $\left(\mathrm{gm} / \mathrm{cm}^{3}\right)$ & 0.823 & 0.920 \\
\hline Calorific value $(\mathrm{kj} / \mathrm{kg})$ & 43000 & 39000 \\
\hline Cetane number & 48 & 47 \\
\hline Kinetic viscosity $\left(\mathrm{at} 40^{\circ} \mathrm{C}\right)[\mathrm{cSt}]$ & 3.9 & 38 \\
\hline Chemical formula & $\mathrm{C}_{14} \mathrm{H}_{22}$ & $\mathrm{C}_{18} \mathrm{H}_{34} \mathrm{O}_{2}$ \\
\hline Flash point $\left({ }^{\circ} \mathrm{C}\right)$ & 56 & 245 \\
\hline Fire point $\left({ }^{\circ} \mathrm{C}\right)$ & 64 & 276 \\
\hline Stoichiometric A/F & 15 & 12.41 \\
\hline Carbon $(\%)$ & 86 & 78.92 \\
\hline Hydrogen $(\%)$ & 14 & 13.41 \\
\hline
\end{tabular}

Table.2 Specification of test engine

\begin{tabular}{|l|l|}
\hline Company and Model & Kirloskar oil Engine, SV1 \\
\hline Type & Single cylinder, 4- Stroke, diesel engine \\
\hline Bore & $87.5 \mathrm{~mm}$ \\
\hline Stroke & $110 \mathrm{~mm}$ \\
\hline Rpm & $1800 \mathrm{rpm}$ \\
\hline Rated power & $8 \mathrm{HP}$ \\
\hline Type of cooling & Water cooled \\
\hline Compression ratio & $16.5: 1$ \\
\hline
\end{tabular}

\section{Experimental Setup And Procedure}

A four stroke, Single cylinder, water cooled diesel engine was used for the performance test. The technical specification of the test engine is shown in Table. 2 The experimental setup diagram is shown in picture. 1 Experiments were carried out initially using neat diesel fuel to generate the base line data. After recording the base line data, tests were carried out using 10 and $20 \%$ biodiesel blends. The engine tests were conducted at various loads and the parameters related to performance were recorded.

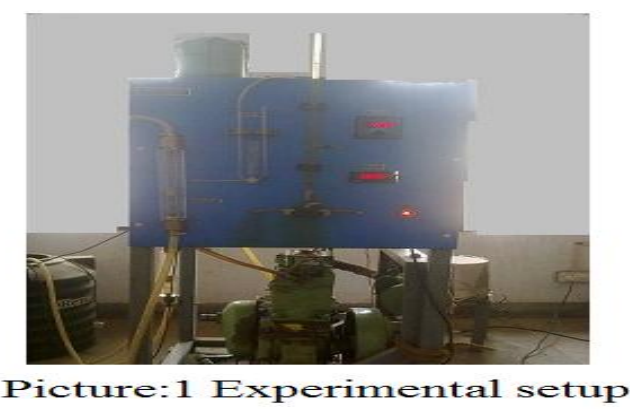

\section{Results And Discussion}

A series of engine tests were carried out using diesel and biodiesel to find out the effect of various blends on the performance of the engine. Investigations are carried out on the engine mainly to the effect of brake specific fuel consumption, air consumption, brake thermal efficiency, heat supplied and speed.

\subsection{Brake specific fuel comsumption}

In fig. 1 compare variation of BSFC for neem oil blended with diesel. BSFC is plotted against the various loads. The BSFC decreases with increase in load; BSFC for B10 is increased by $23.38 \%$ as compared to diesel at maximum load and BSFC for B20 increased by $12.12 \%$ at minimum load and $9.53 \%$ at maximum load as compared to B10. This is caused due to effect of delay in ignition pressure, higher viscosity and lower calorific value of the fuel. 


\subsection{Air consumption}

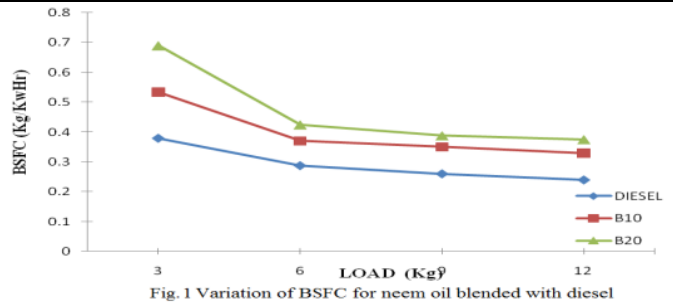

In fig.2 Air consumption rate is plotted against different loads. Air consumption increases with increase in load. The air consumption for B10 is increased by $8.33 \%$, to $11.49 \%$ as compared to diesel and air consumption for B20 is increased by $6.25 \%$ to $9.37 \%$ as compared to B10 at different load, this is due to lower calorific value of fuel.

\subsection{Brake thermal efficiency}

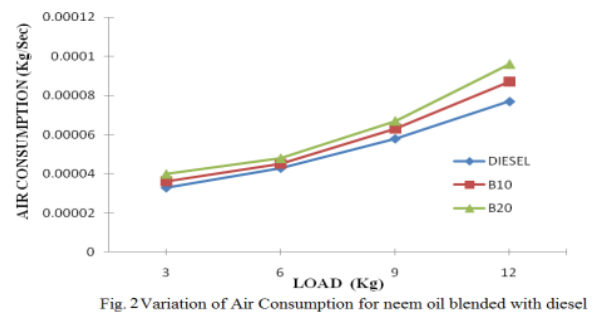

In fig. 3 Brake thermal efficiency is plotted against the various loads for neem oil blended with diesel. The brake thermal efficiency is defined as the actual brake power per cycle divide by the amount of fuel chemical energy. Brake thermal efficiency for B10 is reduced by $21.10 \%$ as compared to diesel at maximum load and BTE for B20 is reduced by $10.52 \%$ as compared to B10 at minimum load and $7.62 \%$ at maximum load. This reduction in brake thermal efficiency with biodiesel blends was due to higher viscosity, poor spray characteristics and lower calorific value. The higher viscosity leads to decreased atomization, fuel vaporization and combustion and hence the thermal efficiency of the biodiesel blends is lower than that of diesel.

\subsection{Heat supply}

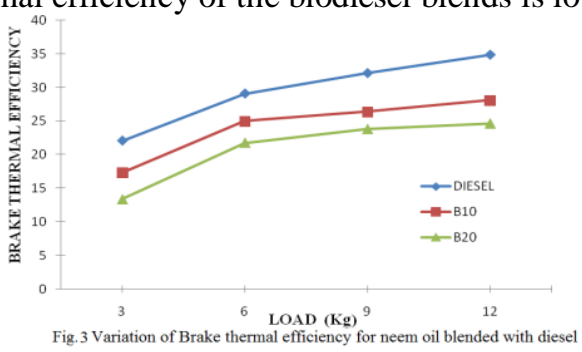

In fig.4 the variation of heat supply for neem oil blended with diesel at various load conditions are plotted. The heat supply increases with increase in load. The heat supply for B10 is increased by $9.86 \%, 7.38 \%$, $8.62 \%$ and $13.08 \%$ as compared to diesel at different load. Similarly for B20 heat supply is increased by $9.84 \%$, $4.85 \%, 6.72 \%$ and $8.988 \%$ as compared to B10 at different load, this is due to lower calorific value, higher viscosity coupled with density of fuel.

\subsection{Speed}

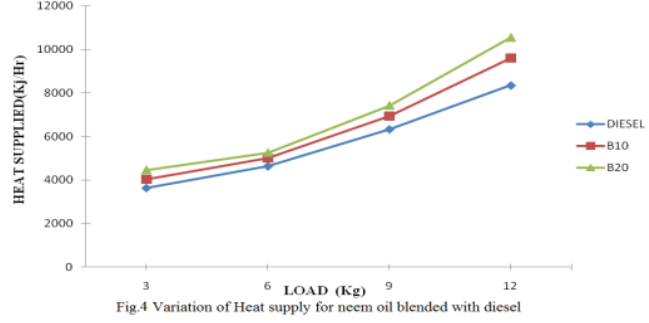

In fig.5 we compared variation of speed for neem oil blended with diesel at various load condition. The speed reduces with increase in load. The Speed for B10 is reduced by $2.19 \%$ as compared to diesel at maximum load and Speed for B20 is reduced by $1.64 \%$ as compared to B10 at maximum load. This is due to lower calorific value of fuel. 


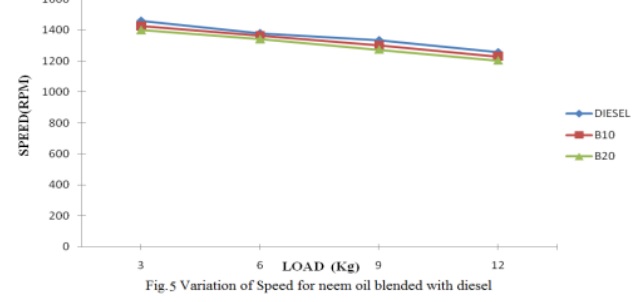

\section{Conclusion}

From the experimental analysis it was found that the blends of neem oil and diesel could be successfully used with acceptable performance up to a certain extent. Based on the result of this study properties of neem oil suggest that it cannot be used directly as CI engine fuel due to higher viscosity, density which will result in low volatility and poor atomization of oil during oil injection in combustion chamber causing incomplete combustion and carbon deposits in combustion chamber. Biodiesel blends produce lower brake thermal efficiency and higher brake specific fuel consumption then diesel because of low calorific value. The properties results of all blends show that blends up to $20 \%$ straight neem oil have value of viscosity and density equivalent to specified range for $\mathrm{CI}$ engine fuel, therefore it can be concluded that up to $20 \%$ blends can be used to run the $\mathrm{CI}$ engine at short term basis.

\section{Acknowledgment}

This experiment has been done in Internal Combustion Engines Laboratory, Department of Mechanical Engineering, University Institute of Technology, RGPV Bhopal, Madhya Pradesh India.

\section{References}

[1] Bala BK. "Studies on biodiesel from transesterification of vegetable oils for diesel engines", Energy Edu Sci Technol, 15:, 2005, 1-43

[2] Kumar SM, Ramesh A, Nagalingam B. "An experimental comparison of method to use methanol and Jatropha oil in compression ignition engine”, Biomass Bio energy, 25;, 2003, 309-18.

[3] Yusuf A, Milford AH, Susan LC. "Fuel properties of tallow and soybean oil esters", JAOS,72(12), 1995, 1557-63.

[4] Ali Y, milford A, Louis HI, Leviticus."Emission and power characteristics of diesel engine on methyl soyate and diesel fuel blends", Bio resource Technology, 52:1995,185-95.

[5] Burnwal BK, Sharma MP. "Prospects of biodiesel production from vegetable oil in India". Renew Sust Energy Rev ; 9:,2005, 363-78.

[6] Srivastava A, Prasad R. "Triglycerides based diesel fuels", Renew Sustain Energy Rev, 4:,2000,11-33.

[7] Puhan S, Vedarman N, Sankaranarayanan G, Bopanna V, Bharat R. "Performance and emission study of mahua oil (madhuca indica oil) ethyl ester in a four stroke natural aspirated direct injection diesel engine", Renew energy:, 2004,1-10.

[8] Karmee SK, Chala A. "Preparation of bio diesel from crude Pongamia pinnata", Bioresour Techno, 96(13):,2005,1425-9.

[9] Anjana Shrivastava and Ram Prasad. "Triglycerides based diesel fuels", Renewable and sustainable energy reviews, Vol.4,pp.,2004, 111-133.

[10] Agrawal, A.K. "Biofuel (alcohols and Biodiesel) Applications as fuels for Internal Combustion Engines", Prog. Energy Combust. Sci, 24, pp.,2007, 125-164.

[11] Sahoo, P.K., Das, L.M, Babu., M.K.G. and Naik, S.N. "Biodiesel development from high acid value polanga seed oil and performasnce evaluation in a CI engine", Bioresource Technology, Vol.86,pp.,2007, 448-454

[12] Srivastava, A., Prasad, R., "Triglycerides-Based Diesel Fuels", Renewable and Sustainable Review, 4, 2, pp., 2002, 111-113.

[13] Sahoo, P.K., Das, L.M.“ Combustion Analysis of Jatropa, Karanja and Polanga based biodieselas fuel in a diesel engine”, fuel, 88,6 , pp.,2009,994-999. 